\title{
Enhanced Oil Recovery from Permian-Carboniferous Deposit of High-Viscosity Oil in the Usinsk Oilfield with Physicochemical and Complex Technologies
}

\author{
Lyubov K. Altunina*a, \\ Vladimir A. Kuvshinova, Ivan V. Kuvshinova, \\ Liubov A. Stasyeva ${ }^{a}$, Michail V. Chertenkov ${ }^{b}$, \\ Dmitry V. Andreev ${ }^{\mathfrak{c}}$ and Alexey Yu. Karmanov ${ }^{\mathrm{c}}$ \\ anstitute of Petroleum Chemistry SB RAS \\ 4 Akademichesky, Tomsk, 634055, Russia \\ ${ }^{\circ}$ LLC "LUKOIL-Engineering" \\ 11 Sretensky Boulevard, Moscow, 101000, Russia \\ cBranch of LLC "LUKOIL-Engineering" "PermNIPIneft" in Perm \\ 9a Heroes of Hasan Str., Perm, 614010, Russia
}

Received 16.08.2018, received in revised form 29.10.2018, accepted 04.12.2018

\begin{abstract}
Presented are the results of laboratory studies, field tests and commercial application of the physicochemical and complex technologies created by IPC SB RAS on the Permian-Carboniferous deposit of high-viscosity oil in the Usinsk oilfield. The technologies are intended to enhance oil recovery and for water shutoff using thermotropic gel-forming and oil-displacing systems under natural development practice and together with thermal-steam stimulation. Technological effectiveness and ecological safety of the technologies and their prospects for commercial application are shown.
\end{abstract}

Keywords: Improved/enhanced oil recovery (IOR/EOR), high-viscosity oils, physicochemical technologies, thermal methods, gels, water shutoff, surfactant compositions, pilot tests, PermianCarboniferous deposits, Usinsk oilfield.

Citation: Altunina L.K., Kuvshinov V.A., Kuvshinov I.V., Stasyeva L.A., Chertenkov M.V., Andreev D.V., Karmanov A.Yu. Enhanced oil recovery from Permian-Carboniferous deposit of high-viscosity oil in the Usinsk oilfield with physicochemical and complex technologies, J. Sib. Fed. Univ. Chem., 2018, 11(4), 462-476. DOI: 10.17516/1998-2836-0091.

(C) Siberian Federal University. All rights reserved

* Corresponding author E-mail address: alk@ipc.tsc.ru 


\title{
Увеличение нефтеотдачи пермо-карбоновой залежи \\ высоковязкой нефти Усинского месторождения \\ физико-химическими и комплексными технологиями (обзор)
}

\author{
Л.К. Алтунина ${ }^{a}$, В.А. Кувшинов ${ }^{a}$, \\ И.В. Кувшинов ${ }^{\text {, }, ~ Л . А . ~ С т а с ь е в а ~}{ }^{a}$, \\ М.В. Чертенков ${ }^{\sigma}$, Д.В. Андреев ${ }^{\text {, А.Ю. Карманов }}{ }^{\text {А }}$ \\ ${ }^{a}$ Институт химии нефти СО РАН \\ Россия, 634055, Томск, пр. Академический, 4 \\ ${ }^{6} О О О$ «ЛУКОЙЛ-Инжиниринг» \\ Россия, 101000, Москва, Сретенский бульвар, 11 \\ ${ }^{\circ}$ Филиал ООО «ЛУКОЙЛ-Инжиниринг» \\ «ПермНИПИнефть» в г. Перми \\ Россия, 614010, Пермь, ул. Героев Хасана, 9 а
}

Приведены результаты лабораторных исследований, промысловых испытаний и промылиленного использования на пермо-карбоновой залежи высоковязкой нефти Усинского месторождения разработанных ИХН СО РАН физико-химических и комплексных технологий увеличения нефтеотдачи и ограничения водопритока с применением термотропных гелеобразующих и нефтевытесняющих композищий при естественном режиме разработки и совместно с паротепловым воздействием. Показана технологическая эффективность и экологическая безопасность технологий, их перспективность для промыиленного использования.

Ключевые слова: увеличение нефтеотдачи, высоковязкие нефти, физико-химические технологии, термические методы, гели, ограничение водопритока, композиции ПАВ, опытнопромышленные испытания, пермо-карбоновая залежь, Усинское месторождение.

\section{Введение}

Запасы тяжелой, высоковязкой нефти в мире примерно в 5 раз превышают объем остаточных извлекаемых запасов легких нефтей малой и средней вязкости. В последние годы доля тяжелой нефти в общей добыче нефти в мире постоянно растет. Поэтому разработке залежей тяжелых, высоковязких нефтей уделяется все большее внимание, особенно в северных областях планеты [1-3]. Это определяет актуальность фундаментальных и прикладных научноисследовательских работ по формированию новых подходов к решению проблем их извлечения. Одним из них является создание физико-химических методов увеличения нефтеотдачи и интенсификации добычи тяжелой нефти как совместно с термическими методами, так и при естественных условиях, без теплового воздействия [4-7].

Современная тенденция развития физико-химических методов увеличения нефтеотдачи базируется на «смарт»-материалах со сложной иерархической структурой. Перспективной представляется разработка систем, химически эволюционирующих непосредственно в пласте с приобретением коллоидно-химических свойств, оптимальных для целей нефтевытеснения.

$$
-463-
$$


Факторами, вызывающими химическую эволюцию инжектированных систем, являются термобарические пластовые условия, взаимодействие с породой коллектора и пластовыми флюидами. В результате химической эволюции систем образуются гели и золи, нефтевытесняющие жидкости с высокой кислотно-основной буферной емкостью, эмульсионные и газожидкостные системы коллоидной степени дисперсности $[7,8]$.

В данной работе приводятся результаты лабораторных исследований и промысловых испытаний геле- и золеобразующих композиций и композиций на основе ПАВ и буферных систем для увеличения нефтеотдачи залежей высоковязких нефтей при естественном режиме разработки и при паротепловом воздействии, реологические и кислотно-основные свойства которых можно регулировать за счет их химической эволюции непосредственно в пласте.

В ИХН СО РАН созданы «интеллектуальные» композиции с регулируемой вязкостью, плотностью и щелочностью: термотропные неорганические и полимерные золе- и гелеобразующие композиции, а также нефтевытесняющие композиции на основе поверхностно-активных веществ (ПАВ) для закачки в нефтяные пласты с целью увеличения нефтеотдачи, снижения обводненности добывающих скважин и интенсификации добычи нефти в осложненных условиях эксплуатации [5-9]. На пермо-карбоновой залежи высоковязкой нефти Усинского месторождения ООО «ЛУКОЙЛ-Коми» предприятия ООО «ЛУКОЙЛ-Инжиниринг» и ООО «ОСК» совместно с ИХН СО РАН с 2003 г. проводят промысловые испытания и осуществляют промышленное использование комплексных технологий паротеплового и физико-химического воздействия, а также «холодных» физико-химических технологий в естественных условиях, без теплового воздействия с целью увеличения нефтеотдачи и интенсификации добычи тяжелой нефти [8-14].

\section{Термотропные гели для увеличения нефтеотдачи и ограничения водопритока}

Для регулирования фильтрационных потоков при заводнении и паротепловом воздействии ИХН СО РАН разработал термотропные гелеобразующие системы: неорганические «соль алюминия - карбамид - вода» (ГАЛКА ${ }^{\circledR}$ ) и полимерные - на основе простых эфиров целлюлозы $\left(\mathrm{METKA}^{\circledR}\right)$, которые в поверхностных условиях являются маловязкими водными растворами, в пластовых условиях под действием тепловой энергии закачиваемого теплоносителя превращаются в гели. Время гелеобразования - от нескольких минут до нескольких суток в интервале температур 20-330 ${ }^{\circ} \mathrm{C}[5-7,9]$.

Гелеобразующую способность термотропных систем изучали путем измерений вязкости и напряжения сдвига с помощью ротационного вискозиметра HaakeRheoStress 600 при температуре от 20 до $150{ }^{\circ} \mathrm{C}$ и давлении до 50 атм в динамических условиях (при всестороннем сжатии). При температуре $100-150{ }^{\circ} \mathrm{C}$ через определенное время раствор превращается в твердообразный гель коагуляционной структуры с резко выраженной тиксотропией и пределом текучести 25-90 Па (рис. 1, 2).

В 2002-2006 гг. на пермо-карбоновой залежи высоковязкой нефти Усинского месторождения, Республика Коми, на поздней стадии разработки проведены промысловые испытания технологий с применением гелеобразующих композиций ГАЛКА ${ }^{\circledR}$ при паротепловом и паро-

$$
-464-
$$


циклическом воздействии, с 2007 г. технологии используются в промышленном масштабе. В 2015-2017 гг. на Усинском месторождении по комплексным технологиям обработаны 185 скважин, дополнительная добыча нефти составила более 800 тыс. т. Применение гелей при площадном воздействии приводит к увеличению охвата пласта закачкой пара, снижению обводненности продукции на 3-45 \%, увеличению дебитов по нефти на 11-33 \% и уменьшению дебитов по жидкости на 14-25 \%. При пароциклическом воздействии прирост дебита по нефти составил от 3 до 24 т в сутки на скважину, дополнительная добыча нефти в среднем 980 т на скважинообработку (рис. 3).

Результаты геофизических исследований $[5,6]$ в паронагнетательных и пароциклических скважинах до и после закачки гелеобразующих композиций показали, что происходит пере-



Рис. 1. Изменение вязкости и напряжения сдвига от времени для раствора композиции ГАЛКА ${ }^{\circledR}-\mathrm{C}_{\mathrm{a}}$ основе системы «соль алюминия - карбамид - вода» (термостатирование при $\mathrm{T}=150{ }^{\circ} \mathrm{C}$ и скорости сдвига $\left.3 \mathrm{c}^{-1}\right)$

Fig. 1. Changes in viscosity and shear stress from time for the GALKA ${ }^{\circledR}-\mathrm{C}$ solution based on the "aluminum salt carbamide - water" system (thermostatting at $\mathrm{T}=150{ }^{\circ} \mathrm{C}$ and shear rate $3 \mathrm{~s}^{-1}$ )

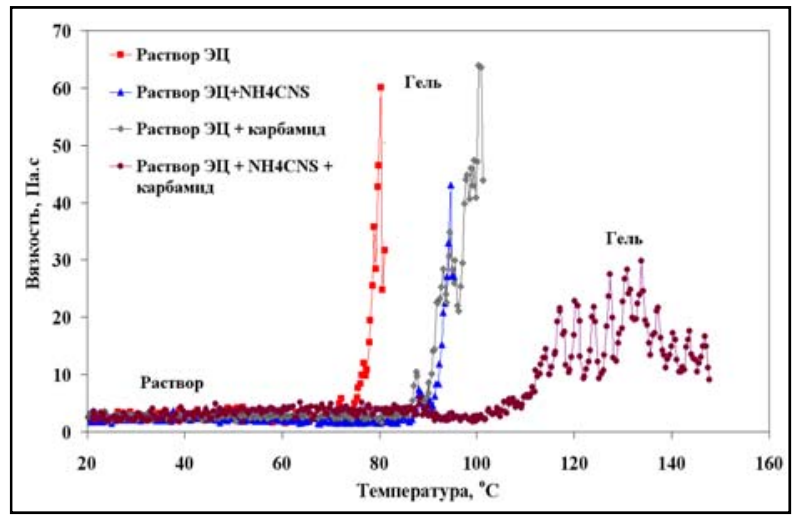

Рис. 2. Изменение вязкости при фазовом переходе раствор - гель для композиций МЕТКА ${ }^{\circledR}$ на основе системы «полимер с НКТР (простой эфир целлюлозы) - вода» при скорости сдвига $3 \mathrm{c}^{-1}$

Fig. 2. The change in viscosity at the solution - gel phase transition for METKA ${ }^{\circledast}$ compositions based on "polymer with LCST (cellulose ether) - water" system at a shear rate of $3 \mathrm{~s}^{-1}$ 

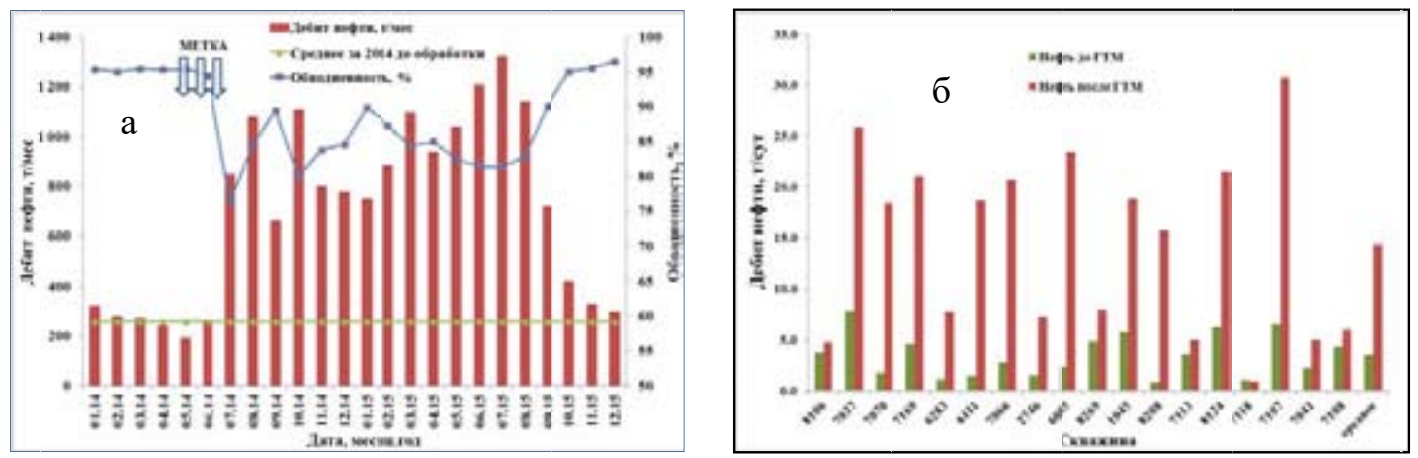

Рис. 3. Результаты работ по ограничению водопритока и увеличению нефтеотдачи на пермокарбоновой залежи Усинского месторождения с применением композиций: METKА $^{\circledR}$ (a) - суммарно по пяти добывающим скважинам, увеличение дебитов по нефти, снижение обводненности; ГАЛКА (б) - промышленное использование технологии в 2017 г., прирост среднемесячного дебита нефти по добывающим скважинам после геолого-технических мероприятий (ГТМ) - пароциклической обработки с композицией ГАЛКА ${ }^{\circledR}$

Fig. 3. The results of works for water shutoff and to enhance oil recovery on the Permian-Carboniferous deposit in the Usinsk oilfield using the following compositions: METKA $^{\circledR}$ (a) - in total for 5 production wells, increased oil production rates and decreased in water cut; GALKA $^{\circledR}(б)-$ commercial use of EOR technology, increase in average monthly oil production rate for production wells after geological and technical measures (GTM) of cyclic steam stimulation with the GALKA ${ }^{\circledR}-\mathrm{C}$ composition in 2017

распределение фильтрационных потоков и увеличение охвата пласта паротепловым воздействием.

С целью повышения эффективности системы паротеплового воздействия за счет селективного ограничения водопритока в 2014 г. произведена закачка композиции МЕТКА ${ }^{\circledR}$ в пять добывающих скважин Усинского месторождения, на участке площадной закачки пара. Объем закачки композиции составлял 19-95 м³ на скважину. После закачки композиции МЕТКА ${ }^{\circledR}$ наблюдается увеличение дебитов по нефти и снижение обводненности продукции (рис. 3). Дополнительно добытая нефть $\sim 1000$ т, или 2100 т на скважину. Длительность эффекта обработки 16 месяцев. По результатам опытно-промышленных работ (ОПР) технология рекомендована к промышленному использованию.

В ИХН СО РАН разработана технология ограничения прорыва газа и воды в добывающих скважинах гелеобразующей композицией ПСБ на основе водорастворимого полимера, аддукта неорганической кислоты и полиола, генерирующей в пласте гель при пластовых температурах. В композициях ПСБ используется водорастворимый полимер с верхней критической температурой растворения, пленки которого имеют наиболее низкую газопроницаемость из промышленных полимеров. Технология применима в интервале температур 0-60 ${ }^{\circ} \mathrm{C}$, на нефтяных месторождениях с терригенными и карбонатными коллекторами, в различных геологофизических условиях и на разных стадиях разработки месторождений. Первые промысловые испытания композиции успешно проведены в конце 2015 г. на пяти добывающих скважинах пермо-карбоновой залежи Усинского месторождения (рис. 4).

Отмечается увеличение добычи нефти, снижение обводненности и дебитов по жидкости. Продолжительность эффекта - 14 месяцев. Дополнительная добыча нефти суммарно по пяти скважинам составила 6500 т, в среднем $\sim 1300$ т на скважину. 


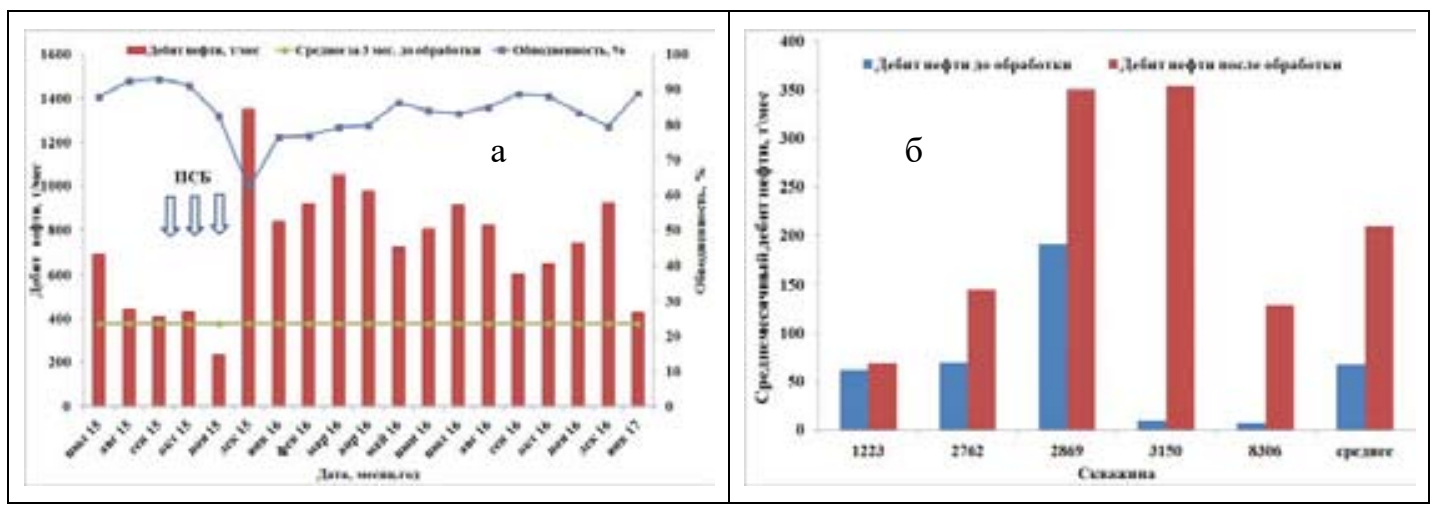

Рис. 4. Результаты ОПР по ограничению водопритока с применением композиции ПСБ на пермокарбоновой залежи Усинского месторождения: а-суммарно по пяти добывающим скважинам, увеличение дебитов по нефти, снижение обводненности; б - прирост среднемесячного дебита нефти за весь период наблюдения (14 мес.) по отдельным скважинам после обработки композицией ПСБ

Fig. 4. The results of pilot tests for water shutoff PSB composition on the Permian-Carboniferous deposit in the Usinsk oilfield: $\mathrm{a}$ - in total for 5 production wells, increased in oil production rates and decreased water cut; $\sigma$ increase in the average monthly production rate during the whole observation period (14 months) for individual wells after stimulation with PSB composition

Для ограничения водопритока и увеличения нефтеотдачи пластов с температурой 60-220 ${ }^{\circ} \mathrm{C}$ при заводнении, паротепловом и пароциклическом воздействии в Институте химии нефти СО РАН созданы высокотемпературные гелеобразующие композиции МЕГА с двумя гелеобразующими компонентами - полимерным и неорганическим, на основе системы «соль алюминия - простой эфир целлюлозы - карбамид - вода» и МЕГА-ПРО на основе системы «соль алюминия - простой эфир целлюлозы - карбамид - полиол - вода», образующие непосредственно в пласте связнодисперсные наноразмерные структуры типа «гель в геле» с улучшенными реологическими характеристиками и структурно-механическими свойствами [10]. Фактором, вызывающим гелеобразование, является тепловая энергия пласта или закачиваемого теплоносителя, без сшивающего агента. При нагревании выше нижней критической температуры растворения эфира целлюлозы в системе за счет фазового перехода сначала образуется полимерный гель, а затем внутри полимерного геля по механизму гидролитической поликонденсации, инициируемой продуктами гидролиза карбамида, образуется гель гидроксида алюминия. В результате улучшаются структурно-механические свойства геля, его вязкость и упругость кратно возрастают.

Растворы композиций МЕГА и МЕГА-ПРО до образования геля являются псевдопластическими жидкостями, зависимость напряжения от скорости сдвига у них имеет нелинейный характер и вязкость зависит от скорости сдвига (рис. $5 a$, б). После образования гелей в растворах этих композиций при различных температурах термотропные системы становятся вязкопластичными телами, способными к упругому восстановлению формы после снятия напряжения (рис. 5в, г).

Гели обладают пространственной структурой, способной сопротивляться сдвигающему напряжению, пока его величина не превысит значение критического (предельного) напряжения сдвига (рис. 5). Затем происходит разрушение структуры геля. Исследования кинетики

$$
-467 \text { - }
$$





Рис. 5. Реологические кривые течения (а, в) и зависимости вязкости $(6$, г) растворов различных композиций от скорости сдвига до термостатирования $\left(\mathrm{a}\right.$, б) и после образования геля при температуре $150^{\circ} \mathrm{C}(\mathrm{B}$, г)

Fig. 5. Rheological flow curves $(\mathrm{a}, \mathrm{B})$ and viscosity dependencies $(\sigma, \Gamma)$ of the solutions of various compositions on shear rate before thermostatting $(\mathrm{a}, \sigma)$ and after gelation at $150^{\circ} \mathrm{C}(\mathrm{B}, \Gamma)$

гелеобразования и реологических свойств растворов и гелей показали, что полученная синергетическая связнодисперсная наноразмерная структура типа «гель в геле» имеет повышенную вязкость, упругость и предельное напряжение сдвига по сравнению с гелями с одним гелеобразующим компонентом (рис. 5).

Образующиеся в пласте гели сдерживают прорыв воды или пара из нагнетательных в добывающие скважины, перераспределяют фильтрационные потоки пластовых флюидов в нефтяном пласте, что приводит к стабилизации либо снижению обводненности продукции окружающих добывающих или пароциклических скважин, увеличению добычи нефти.

Первые ОПР по технологии с применением гелеобразующей наноструктурированной композиции МЕГА для ограничения водопритока и увеличения нефтеотдачи проведены в конце 2016 г. на пяти добывающих скважинах пермо-карбоновой залежи Усинского месторождения при пароциклической обработке (ПЦО) и в зоне площадной закачки пара. Объем закачиваемой композиции составлял 80-120 м³ на скважину. После обработки скважин наблюдается значительное снижение обводненности, на $12-40$ \%, и кратное увеличение дебитов по нефти (рис. 6).

Результаты ОПР подтверждают возможность композиции МЕГА эффективно блокировать поступление воды в добывающую скважину при ПЦО и в зоне паротеплового воздействия. 



Рис. 6. Ограничение водопритока и увеличение добычи нефти композицией МЕГА суммарно по пяти добывающим скважинам Усинского месторождения, 2016-2017 гг.

Fig. 6. Water shutoff and increased oil production with the MEGA composition in total for 5 production wells in the Usinsk oilfield, 2016-2017

\section{Нефтевытесняющие композиции на основе ПАВ} для увеличения нефтеотдачи

В ИХН СО РАН разработаны композиции на основе ПАВ и буферных систем для увеличения нефтеотдачи залежей высоковязких нефтей при естественном режиме разработки, а также при паротепловом воздействии на пласт, которые химически эволюционируют непосредственно в пласте с приобретением коллоидно-химических свойств, оптимальных для нефтевытеснения (композиции НИНКА ${ }^{\circledR}$, загущенная НИНКА-З, ГБК и ИХН-ПРО), их реологические и кислотно-основные свойства можно регулировать в зависимости от геолого-физических условий месторождений [9, 12-14].

На пермо-карбоновой залежи Усинского месторождения проведены промысловые испытания нефтевытесняющих композиций НИНКА ${ }^{\circledR}$ на основе ПАВ, солей аммония и карбамида, генерирующих в пласте при паротепловом воздействии $\mathrm{CO}_{2}$ и щелочную буферную систему, которые способствуют снижению вязкости нефти и дополнительному ее вытеснению. Установлено, что их применение при стационарной закачке пара приводит к снижению обводненности на 10-20 \% и увеличению дебитов по нефти в среднем на 40 \%. При пароциклическом воздействии наблюдается увеличение добычи нефти в 1.5-3 раза (например, рис. 7) (2017 г.), уменьшение вязкости нефти в 2-3 раза $[9,12]$.

Показана перспективность комплексной технологии чередующейся закачки пара, термотропных гелеобразующих и нефтевытесняющих композиций. Технология используется в промышленном масштабе. В 2008-2011 гг. после закачки композиций ГАЛКА ${ }^{\circledR}-\mathrm{C}$ и НИНKA $^{\circledR}$ в 41 паронагнетательную скважину Усинского месторождения в добывающих скважинах наблюдалось увеличение дебитов по нефти на 4-30 т/сут, снижение обводненности на 5-20\% (рис. 8). В 2014-2016 гг. успешно проведена закачки композиций ГАЛКА ${ }^{\circledR}-\mathrm{C}$ и НИНКА ${ }^{\circledR}$ в 82 паронагнетательные скважины. Результаты проведенных работ показывают синергизм методов паротеплового и физико-химического воздействия на пласт, перспективность их комплексного применения для увеличения нефтеотдачи залежей высоковязких нефтей. 


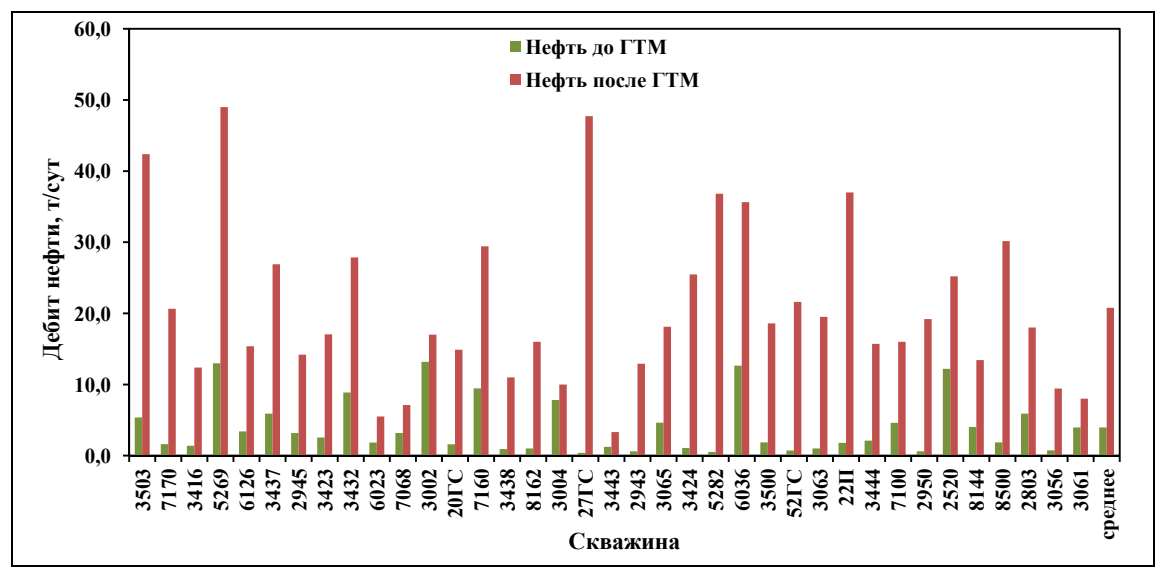

Рис. 7. Результаты промышленного использования технологии увеличения нефтеотдачи на пермокарбоновой залежи Усинского месторождения с применением композиции НИНКА ${ }^{\circledR}$ прирост среднемесячного дебита нефти по добывающим скважинам после пароциклической обработки с композицией НИНКА ${ }^{\circledR}$ в 2017 г.

Fig. 7. The results of commercial use of EOR technology on the Permian-Carboniferous deposit in the Usinsk oilfield using the NINKA ${ }^{\circledR}$ composition - increased average monthly oil production rate for production wells after cycle steam stimulation with the NINKA ${ }^{\circledR}$ composition in 2017



Рис. 8. Анализ эффективности промышленного применения в 2008-2011 гг. технологий повышения нефтеотдачи на Усинском месторождении: увеличение добычи нефти в добывающих скважинах в результате закачки композиций ГАЛКА ${ }^{\circledR}-С$ и НИНКА ${ }^{\circledR}$ в 41 паронагнетательную скважину

Fig. 8. The analysis of the commercial application of EOR technologies in the Usinsk oilfield in 2008-2011: increased oil production in producing wells due to injection of the GALKA $^{\circledR}-\mathrm{C}$ and NINKA ${ }^{\circledR}$ compositions into 41 steam injection wells 
Для увеличения и коэффициента нефтевытеснения, и коэффициента охвата залежей высоковязких нефтей, разрабатываемых паротепловым воздействием, создана загущенная нефтевытесняющая композиция на основе ПАВ, солей аммония, алюминия и карбамида (НИНКА-З), которая является одновременно потокоотклоняющей и нефтевытесняющей композицией [11, 12]. В пласте при тепловом воздействии карбамид гидролизуется, образуя $\mathrm{CO}_{2}$ и $\mathrm{NH}_{3}$, который с солью аммония дает щелочную аммиачную буферную систему, оптимальную для целей нефтевытеснения. Повышение $\mathrm{pH}$ вызывает гидролиз соли алюминия с образованием золя гидроксида алюминия, при этом вязкость композиции увеличивается на 1-2 порядка (рис. 9). Это приводит к увеличению охвата пласта тепловым воздействием, подключению низкопроницаемых пропластков, снижению вязкости нефти и ее доотмыву. В результате происходит увеличение коэффициента охвата пласта, прирост коэффициента извлечения нефти (КИН) и интенсификация ее добычи.

Исследования кинетики образования золя и реологических свойств растворов и золей, полученных при 90, 150 и $200{ }^{\circ} \mathrm{C}$, показали, что после термостатирования растворов золеобразующей нефтевытесняющей композиции с регулируемой вязкостью и щелочностью, в зависимости от концентрации соли алюминия, вязкость растворов композиции увеличивается в 6-78 раз, рН растворов композиции после термостатирования повышается до 7.7-10.1 ед. pH. В качестве примера на рис. 9 приведены результаты исследования реологических свойств раствора композиции (концентрация соли алюминия $2.5 \%$ до и после образования золя в результате термостатирования при $150{ }^{\circ} \mathrm{C}$ в течение 5 ч. Измерения проводили после охлаждения раствора до $20^{\circ} \mathrm{C}$. До термостатирования композиция является ньютоновской жидкостью, после образования золя - вязкопластичной (рис. 9).

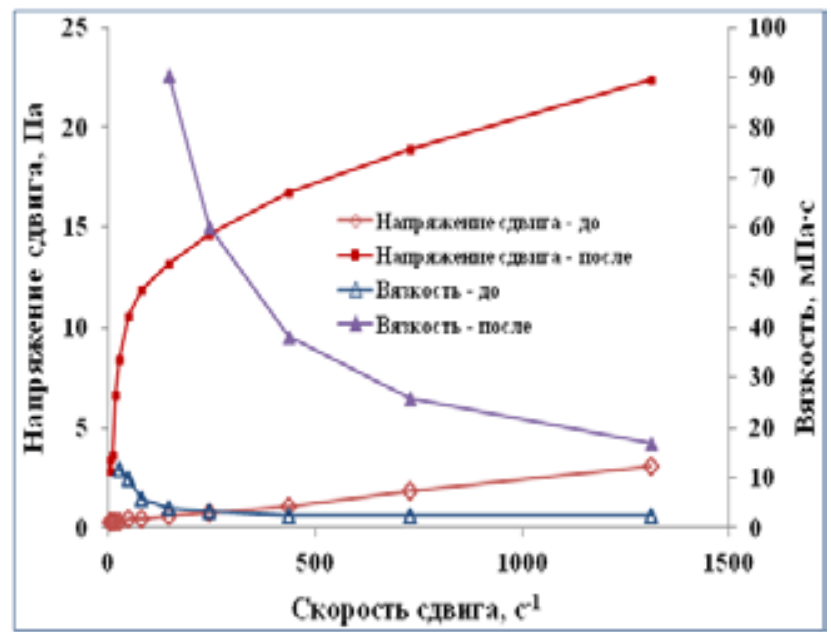

Рис. 9. Полные реологические кривые течения и зависимость вязкости раствора золеобразующей нефтевытесняющей композиции НИНКА-3 до и после 5 ч термостатирования при $150{ }^{\circ} \mathrm{C}$ : до термостатирования композиция является ньютоновской жидкостью, после образования золя вязкопластичной

Fig. 9. Complete rheological flow curves and viscosity dependence of the solution of the sol-forming oil-displacing NINKA-Z composition before and after 5 hour thermostatting at $150{ }^{\circ} \mathrm{C}$ : before thermostatting the solution of the composition is Newtonian fluid, while after solation - a viscoplastic fluid 


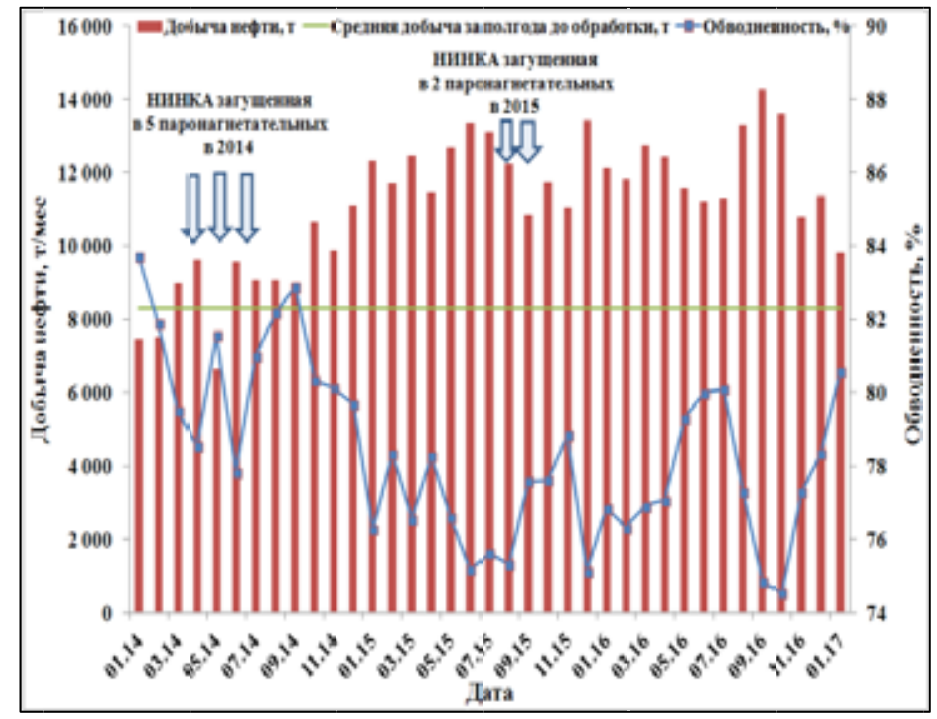

Рис. 10. Увеличение дебитов по нефти и снижение обводненности до и после закачки композиции НИНКА-3 в 2014-2015 гг. в паронагнетательные скважины на опытном участке ПТВ-Юго-Запад пермокарбоновой залежи Усинского месторождения

Fig. 10. The increased oil production rates and decreased water cut before and after injection of the NINKA-Z composition into steam injection wells in the PTV-South-West test area on the Permian-Carboniferous deposit in the Usinsk oilfield in 2014-2015

В 2014-2015 гг. были проведены промысловые испытания композиции, выполнена закачка загущенной композиции НИНКА-3 в семи паронагнетательных скважинах, расположенных на участке паротеплового воздействия (ПТВ) пермо-карбоновой залежи Усинского месторождения, Республика Коми. Объем закачки составлял 80-110 м³ на скважину, отслеживание эффекта проводилось по 75 добывающим скважинам участка. Наблюдается устойчивое снижение обводненности продукции и повышение добычи нефти после закачки (рис. 10), особенно заметное через 3 месяца после обработки, что обусловлено скоростью движения фронта жидкости между нагнетательными и добывающими скважинами. Суммарный эффект по участку более 70 тыс. т дополнительно добытой нефти.

\section{«Холодные» физико-химические технологии увеличения нефтеотдачи залежей тяжелой нефти}

Большие резервы увеличения нефтеотдачи залежей тяжелой нефти могут быть реализованы за счет использования «холодных» физико-химических технологий, в частности, путем закачки в продуктивные пласты различного рода композиций химических реагентов. Перспективны химически эволюционирующие системы, включающие композиции, способные химически реагировать с породой пласта и пластовыми флюидами: композиции последовательно, в процессе движения в пласте, меняют свой состав и свойства, в частности, будучи вначале кислотными породорастворяющими, после взаимодействия с породой становятся нейтральными или щелочными нефтевытесняющими и золеобразующими композициями. Традиционно химически эволюционирующие системы развиваются в форме кислотных композиций в на- 
правлении усложнения их состава с расширением спектра полезных функций. Наряду с известными кислотами начинают использоваться комплексные кислоты, образующиеся в результате донорно-акцепторного взаимодействия компонентов композиции. Состав и свойства комплексных кислот регулируются концентрациями и соотношением донора и акцептора. Комплексные кислоты обладают поверхностно-активными свойствами, могут увеличивать нефтеотдачу низкопроницаемой матрицы пласта одновременно за счет растворения и капиллярной противоточной пропитки матрицы.

В системах «неорганическая поликислота - полиол» за счет донорно-акцепторного взаимодействия образуются комплексные кислоты, намного более сильные, чем исходная кислота. Донорно-акцепторное взаимодействие позволяет усилить кислотность нефтевытесняющих композиций и увеличить продолжительность их действия в пласте за счет повышения буферной емкости и расширения диапазона буферного действия в кислой области рН. На рис. 11 приведена схема образования комплексной кислоты и ее диссоциации на ионы на примере взаимодействия борной кислоты и глицерина.

Атом кислорода гидроксильной группы в молекуле глицерина - донор отдает свою неподеленную электронную пару на свободную орбиталь акцептора - атома бора в молекуле борной кислоты. В результате из одной молекулы борной кислоты и двух молекул глицерина образуется молекула координационного соединения - глицеринборная кислота, на четыре порядка более сильная, чем борная кислота.

Для увеличения нефтеотдачи пластов с низкой температурой, $20-40{ }^{\circ} \mathrm{C}$, охлажденных закачкой воды, а также залежей высоковязких нефтей при естественном режиме разработки, в отсутствие паротеплового воздействия, в ИХН СО РАН разработаны нефтевытесняющие композиции на основе ПАВ, неорганической буферной системы и полиола с регулируемой вязкостью и щелочностью: щелочная композиция ИХН-ПРО на основе неорганической буферной системы и кислотная композиция ГБК пролонгированного действия на основе аддукта неорганической кислоты $[7,9,11,13]$. Композиции имеют температуру замерзания минус $20 \div$ минус $60{ }^{\circ} \mathrm{C}$, низкое межфазное натяжение на границе с нефтью, регулируемую плотность, от 1.1 до



Кислотная композиция ГБК наиболее эффективна в карбонатных коллекторах, имеет замедленную реакцию с карбонатными породами, не образует нерастворимых продуктов, восстанавливает исходную проницаемость коллектора. В результате взаимодействия композиции с карбонатным коллектором выделяется $\mathrm{CO}_{2}$, который растворяется в нефти и снижает ее вязкость, что способствует увеличению степени извлечения нефти. Кроме того, в результате взаимодействия с карбонатным коллектором и гидролиза карбамида, входящего

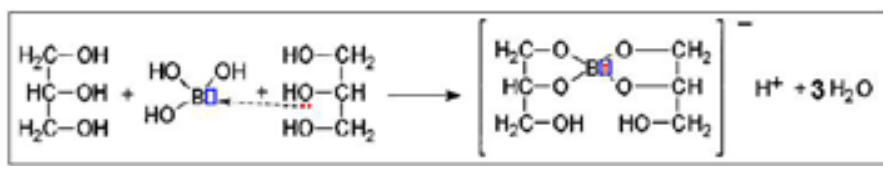

Рис. 11. Донорно-акцепторное взаимодействие борной кислоты и глицерина с образованием комплексной глицеринборной кислоты

Fig. 11. Donor-acceptor interaction of boric acid with glycerine to form complex glycerine-boric acid 

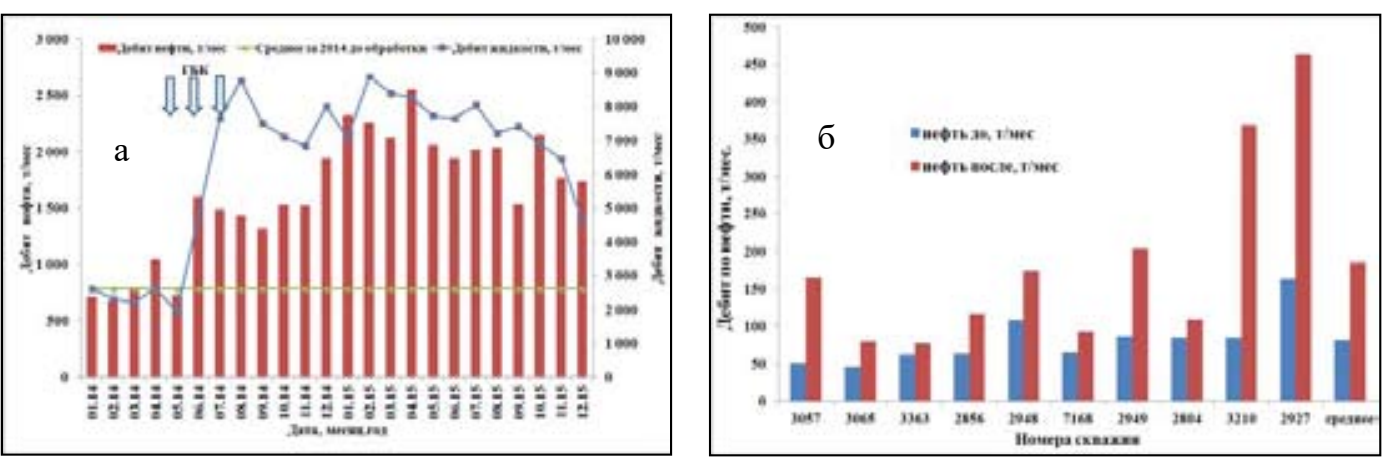

Рис. 12. Результаты ОПР с применением кислотной композиции ГБК пролонгированного действия на низкопродуктивных добывающих скважинах пермо-карбоновой залежи Усинского месторождения: a - суммарно по 10 добывающим скважинам, увеличение дебитов по нефти, снижение обводненности; б - среднее значение месячных дебитов по нефти для отдельных скважин за весь период наблюдения (19 мес.) до и после обработки композицией ГБК

Fig. 12. The results of pilot tests using acidic GBK composition of the prolonged action in low-productive producing wells on the Permian-Carboniferous deposit in the Usinsk oilfield: a - in total for 10 producing wells, increased oil production rates and decreased water cut; $\sigma$ - the average value of monthly oil production rates for individual wells over the whole observation period (19 months) before and after stimulation with the GBK composition

в состав композиции, ее $\mathrm{pH}$ повышается с 2.8-3.1 до 8.8-10.0 и она химически эволюционирует, превращаясь в щелочную нефтевытесняющую композицию, обеспечивающую эффективное нефтевытеснение и пролонгированное воздействие на пласт. После термостатирования с композицией ГБК и карбонатным коллектором при температуре $70-120{ }^{\circ} \mathrm{C}$ вязкость нефти снижается в 1.2-2.7 раза.

В 2014 г. после закачки композиции ИХН-ПРО в пять и ГБК в десять низкопродуктивных добывающих скважин Усинского месторождения без теплового воздействия (рис. 12) дебиты по нефти увеличились на 5.5-14.8 т/сут, по жидкости - на 15-25 м³/сут. Дополнительно добытая нефть составила 28 тыс. т, 1600-2000 т/скв. Технологии были рекомендованы к промышленному применению. Все компоненты композиций являются экологически безопасными продуктами многотоннажного промышленного производства.

\section{Заключение}

Результаты проведенных работ показывают перспективность промышленного использования технологий с применением термотропных гелеобразующих и нефтевытесняющих композиций в труднодоступных регионах и сложных природно-климатических условиях, при их реализации используется стандартное нефтепромысловое оборудование и экологически безопасные продукты многотоннажного промышленного производства.

Масштабное промышленное применение новых комплексных технологий увеличения нефтеотдачи, сочетающих базовое воздействие на пласт закачкой воды или водяного пара с физико-химическими методами, увеличивающими охват пласта базовым воздействием и коэффициент нефтевытеснения при одновременной интенсификации разработки, позволит продлить рентабельную эксплуатацию месторождений, находящихся на поздней стадии разработ- 
ки, и вовлечь в разработку месторождения с трудно извлекаемыми запасами углеводородного сырья, в том числе залежи высоковязких нефтей.

Работа выполнена в рамках проекта «V.46.2.3. Физическая химия и реология нефти и полидисперсных нефтесодержацих систем в процессах увеличения нефтеотдачи пластов и транспорта нефти (№ 0370-2018-0007)».

\section{Список литературы}

1. Тарасюк В.М. Высоковязкие нефти и природные битумы. Экологический вестник России 2014. № 6, C. 22-27. [Tarasyuk V.M. High viscosity oils and natural bitumen. Ecological Bulletin of Russia 2014. No. 6, P. 22-27. (In Russ.)]

1. Zolotukhin A.V., Gudmestad O.T., Yarlsbyu E.T. Resources of oil and gas, development of offshore deposits. WIT press, Southampton, Great Britain, 2011. $279 \mathrm{p}$.

2. Ruzin L.M., Morozyuk O.A., Durkin S.M. Features and innovative ways of highly viscous oil field development. Oil Industry 2013. No. 8, P. 51-53.

3. Romero-Zeron Laura. Chemical Enhanced Oil Recovery (cEOR)-A Practical Overview. ISBN 978-953-51-2701-7, Print ISBN 978-953-51-2700-0, InTech, 2016, 200 p. DOI:10.5772/61394.

4. Altunina L., Kuvshinov V., Kuvshinov I. Promising physical-chemical IOR technologies for Arctic oilfields. Society of Petroleum Engineers - SPE Arctic and Extreme Environments Conference and Exhibition. AEE 2013. Vol. 2, P. 1057-1082.

5. Altunina L.K. and Kuvshinov V.A. Physicochemical methods for enhanced oil recovery in oilfields (review). Russian Chemical Reviews 2007. Vol. 76(10), P. 971-987.

6. Алтунина Л.К., Кувшинов В.А., Стасьева Л.А., Кувшинов И.В. Тенденции и перспективы развития физико-химических методов увеличения нефтеотдачи месторождений тяжелой нефти. Химия в интересах устойчивого развития 2018. Т. 26. № 3, C. 261-277. [Altunina L.K., Kuvshinov V.A., Stasyeva L.A., Kuvshinov I.V. Trends and Perspectives of Development of PhysicalChemical Methods Enhanced Oil Recovery of Heavy Oil Fields. Chemistry for Sustainable Development 2018. Vol. 26(3), P. 261-277. (In Russ.)]

7. Altunina L.K., Kuvshinov I.V., Kuvshinov V.A., Stasyeva L.A. Chemically evolving systems for oil recovery enhancement in heavy oil deposits. Proceedings of the International Conference on Advanced Materials with Hierarchical Structure for New Technologies and Reliable Structures (AMHS'17). AIP Conference Proceeding 2017. Vol. 1909(1), P. 020005. Published by the American Institute of Physics. https://doi.org/10.1063/1.5013686

8. Алтунина Л.К., Кувшинов В.А., Кувшинов И.В., Стасьева Л.А., Чертенков М.В., Шкрабюк Л.С., Андреев Д.В. Физико-химические и комплексные технологии увеличения нефтеотдачи пермо-карбоновой залежи высоковязкой нефти Усинского месторождения. Нефтяное хозяйство 2017. № 7, C. 26-29. [Altunina L.K., Kuvshinov V.A., Kuvshinov I.V., Stasyeva L.A., Chertenkov M.V., Shkrabyuk L.S.Andreev D.V. Physical-chemical and complex EOR/IOR technologies for the Permian-Carboniferous deposit of heavy oil of the Usinskoye oil field. Oil Industry 2017. Vol. 7, P. 26-29. (In Russ.)]

9. Алтунина Л.К., Кувшинов В.А., Кувшинов И.В., Стасьева Л.А., Козлов В.В, Чертенков М.В., Шкрабюк Л.С. Технология «гель в геле». Увеличение нефтеотдачи тяжелых высо- 
ковязких нефтей. Oil\&Gas Russia 2017. № 7 (1117), C. 28-34. [Altunina L.K., Kuvshinov V.A., Kuvshinov I.V., Stasyeva L.A., Kozlov V.V., Chertenkov M.V., Shkrabyuk L.S. "GEL in GEL" TECHNOLOGY. Increasing recovery of heavy high-viscosity crudes. Oil\&Gas Russia 2017. Vol. 7(1117), P. 28-34. (In Russ.)]

10. Altunina L.K., Kuvshinov V.A., Kuvshinov I.V., Chertenkov M.V., Ursegov S.O. Pilot tests of new EOR technologies for heavy oil reservoirs. Proceedings of SPE Russian Petroleum Conference, Moscow 2015, Paper 176703-MS. Flash-memory.

11. Алтунина Л.К., Кувшинов В.А., Стасьева Л.А., Кувшинов И.В., Козлов В.В. Нефтевытесняющая композиция ПАВ с регулируемой вязкостью для увеличения нефтеотдачи залежей высоковязких нефтей. Георесурсы 2016. T. 18. № 4. Ч. 1, С. 281-288. [Altunina L.K., Kuvshinov V.A., Stasyeva L.A., Kuvshinov I.V., Kozlov V.V. Oil-displacing driving surfactant composition with controlled viscosity to enhance oil recovery from high-viscosity oil deposits. Georesources 2016. Vol. 18(4). Part 1, P. 281-288. (In Russ.)]

12. Алтунина Л.К., Кувшинов В.А., Кувшинов И.В., Чертенков М.В. «Холодные» технологии повышения нефтеотдачи. Oil\&Gas Journal. 2016. № 1-2, C. 80-84. [Altunina L.K., Kuvshinov V.A., Kuvshinov I.V., Chertenkov M.V. «Cold» technologies for enhanced oil recovery. Oil\&Gas Journal. 2016. Vol. 1-2, P. 80-84. (In Russ.)]

13. Kuvshinov I.V., Kuvshinov V.A., Altunina L.K. Field experience of thermotropic compositions application for enhanced oil recovery. Oil Industry 2017. Vol. 1, P. 44-47. 